\title{
“Got mentorship?"
}

\author{
Tara Karamlou, MD
}

\footnotetext{
From the Division of Pediatric Cardiac Surgery, Department of Surgery, University of California San Francisco, San Francisco, Calif.

Disclosures: Author has nothing to disclose with regard to commercial support.

Received for publication Feb 23, 2016; accepted for publication Feb 25, 2016; available ahead of print March 24, 2016.

Address for reprints: Tara Karamlou, MD, Division of Pediatric Cardiac Surgery, Department of Surgery, Benioff Childrens' Hospital, 550 16th St, Fifth Floor 5-741, San Francisco, CA 94143 (E-mail: tkaramlou@ gmail.com).

J Thorac Cardiovasc Surg 2016;151:1460-1

$0022-5223 / \$ 36.00$

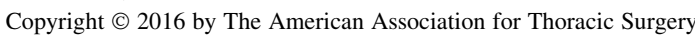

http://dx.doi.org/10.1016/j.jtcvs.2016.02.055
}

I am grateful to the Journal for publishing such educational papers as "Transition to Practice in Pediatric Cardiac Surgery: Preparation, Execution, and Balance," by Carillo and DiBardino in this issue. ${ }^{1}$ All junior surgeons can benefit from the authors' insightful, pragmatic advice, and all junior surgeons will gain confidence from the knowledge that most had a healthy degree of trepidation during his or her first case as an attending. The authors discuss 3 crucial aspects of a successful segue into the field of pediatric cardiac surgery: a careful, studied choice of the initial job, predicated mainly on the presence of an engaged mentor; the development of a well-defined niche, buttressed by established relationships with referring providers; and the pursuit of nonclinical activities, including scholarly research, participation in hospital-based committees, and application for supportive grant funding. Certainly all of these criteria are important in building a productive and rewarding career as a pediatric cardiac surgeon; nonetheless, I would postulate (as do the authors) that identification of a mentor and continued, active engagement in a mentorial relationship is the single most critical ingredient.

The term "mentorship" was inspired by the character of Mentor in Homer's Odyssey. The actual Mentor in the story is a slightly ineffectual elderly man, but the goddess Athena assumes his appearance to guide young Telemachus during trying times. Despite its roots in antiquity, the concept of mentorship is intensely personal, and therefore elusive, as evidenced by the existence of more than 50 million definitions of it. One particular definition will resonate with most evolving congenital heart surgeons: "Mentoring is a process for the informal transmission of knowledge, social capital, and the psychosocial support perceived by the recipient as relevant to work, career, or professional development; mentoring entails informal communication, usually face-to-face and during a sustained period of time, between a person who is perceived to have greater relevant knowledge, wisdom, or experience (the mentor) and a person who is perceived to have less (the protégé).",2

My one critique of this paper is that the inadequate discussion of those ingredients inherent in effective

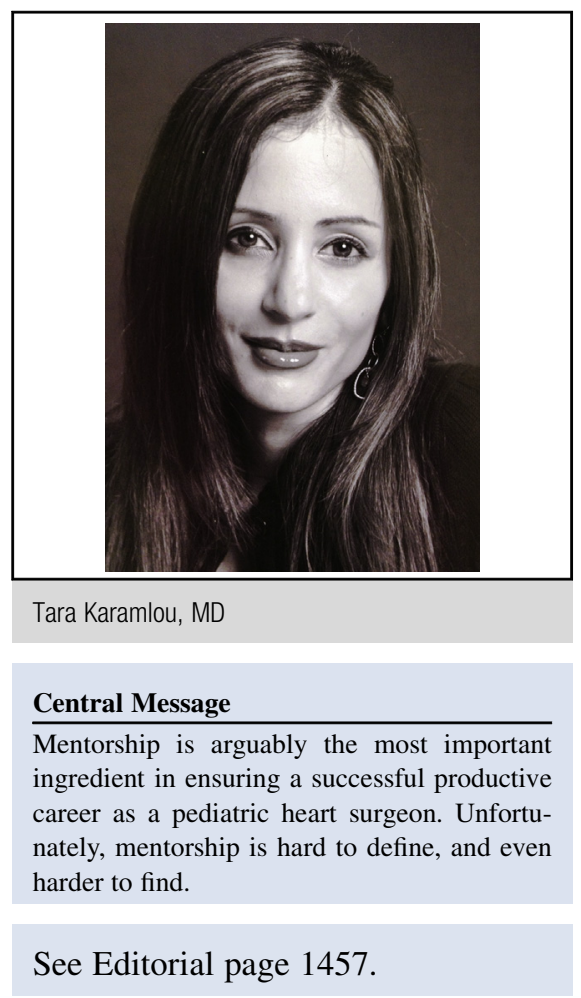

mentoring relationships. The authors discuss introspection and self-reflection. Their comment about keeping a personal journal following any adverse outcome as a facilitator of such reflection is critical. I would argue that junior surgeons should keep a diary and record one "pearl" following every case. Diagrams and illustrations can be extremely helpful adjuncts. The authors rightly point out the modicum of protection provided by a senior surgeon's involvement; however, despite the utility of this advice, they fail to synthesize a useful lexicon of mentorship for young surgeons.

How can one identify a suitable mentor? Is there a conceptual framework that can be applied to optimize these relationships? I was surprised to learn that some businesses, recognizing the value of mentorship, have transitioned to automated mentor-mentee matching using Mentor Scout software. In the absence of such innovative solutions in the realm of cardiac surgery, I would offer the following impressions. Behaviors that should be considered requirements on the part of both the mentor and the mentee include taking initiatives and risks, accepting each other, establishing specific goals and timelines for achievement of these goals, and dealing effectively with unmet expectations or objectives with honest, timely feedback. 
Designation of scheduled, regular meetings that are more frequent at the outset will facilitate open communication and enhance trust. The topics should include, at times, inquiries into the status of work-life balance, extraneous stressors, and health and wellness. Accurate and fair evaluation of a junior surgeon's progress should account for every aspect of the individual and not rely solely on the technical machinations of a particular case.

In my opinion, mentorship is evoked most successfully by graded responsibility rather than by micromanagement. Therefore, mentorship would be impeded by direct involvement of the mentor in every surgical case-a situation that for many junior surgeons could hinder progression and eventual transition to becoming a more independent surgeon. Although appropriate supervision is critical to the "safe" development of pediatric heart surgeons, especially in this era of enhanced scrutiny and transparency, active engagement by both parties may mitigate any perceived discordance between expectations and reality.

Mentorship transcends the professional relationship and ventures into a much deeper and thus complex interchange between the mentor and the mentee. Mentored relationships are challenged by the often-conflicting desire of the mentee to develop autonomy and independence and the desire of the mentor to protect patients, outcomes, and, of course, the mentored individual. Unfortunately (and likely the reason why Carillo and DiBardino avoided a deeper dive into mentorship per se), the quality of a mentoring relationship cannot be evaluated by extraneous individuals or tools. Ultimately, the best metric of success is that of a once-junior surgeon who is well-balanced and happy, and whose achievements have far surpassed those of his or her mentor. Steven Spielberg best encapsulated the complexities of a mentorial relationship among surgeons: "The delicate balance of mentoring someone is not creating them in your own image, but giving them the opportunity to create themselves." 3

\section{References}

1. Carillo SA, DiBardino DJ. Transition to practice in pediatric cardiac surgery: preparation, execution, and balance. J Thorac Cardiovasc Surg. 2016;151:1457-9.

2. Bozeman B, Feeney MK. Toward a useful theory of mentoring: a conceptual analysis and critique. Administr Soc. 2007:39:719-39.

3. Spielberg S. Quoted by: Quoteur. Available at: http://quoteur.com. Accessed March 1, 2016. 